\title{
Smart wearable devices for human exposure vibration measurements on two-wheel vehicles
}

\author{
Marco Carratù ${ }^{1}$, Antonio Pietrosanto ${ }^{1}$, Paolo Sommella ${ }^{1}$, Vincenzo Paciello \\ ${ }_{1}^{1}$ University of Salerno, Via Giovanni Paolo II 132, 84084 Fisciano (SA), Italy \\ 2 University of Cassino and Southern Lazio, Via di Biasio 43, 03043 Cassino (FR), Italy
}

\begin{abstract}
The comfort experienced while driving a motorcycle is becoming a subject of great importance; indeed, the driver is exposed to vibrations that are typically caused by irregular profiles or wear of the road surface as well as by the aerodynamic influence and highfrequency rotation of the motorcycle engine. This paper discloses an original solution that allows the driver to monitor their exposure to vibration during a ride using a low-cost wearable device (smartwatch). A suitable measurement system has been designed and tested using a real motorcycle. The system captures acceleration signals in real time through Bluetooth communication and interfaces with a wearable device with a microcontroller unit that calculates vibrations transmitted through the driver's hands. Different indexes proposed in the literature are adopted for the comfort analysis in both time and frequency domains. The hand transmitted vibrations are also experimentally compared with those measured through a fixed accelerometer according to the prescription included in the standard ISO 5349 to show the feasibility of the proposed approach in typical application conditions.
\end{abstract}

Section: RESEARCH PAPER

Keywords: vibrations; wearable device; accelerometer; ISO- 5349; suspension system

Citation: Marco Carratù, Vincenzo Paciello, Antonio Pietrosanto, Paolo Sommella, Smart wearable devices for human exposure vibration measurements on two-wheel vehicles, Acta IMEKO, vol. 9, no. 4, article 16, December 2020, identifier: IMEKO-ACTA-09 (2020)-04-16

Section Editor: Francesco Bonavolonta, University of Naples Federico II, Italy

Received October 16, 2019; In final form December 2, 2019; Published December 2020

Copyright: This is an open-access article distributed under the terms of the Creative Commons Attribution 3.0 License, which permits unrestricted use, distribution, and reproduction in any medium, provided the original author and source are credited.

Corresponding author: Marco Carratù, e-mail: mcarratu@unisa.it

\section{INTRODUCTION}

Body vibration is a term used when vibrations (mechanical oscillations) of any frequency are transferred to the human body. People are exposed to many different types of vibrations in their daily lives; for example, consider the time spent in a vehicle (car, train, plane, motorcycle, etc.) or the use of power tools. Vibration experienced as part of a particular type of work can become a potential form of professional risk, particularly after years of exposure [1].

Humans are exposed to vibration through a contact surface that is in a mechanical vibrating state. In recent years, human exposure to vibrations has increased progressively with the development of agricultural, industrial mechanisation and the use of vehicles.

Due to this increased use of vehicles in recent decades, many people spend at least an hour a day in a vehicle, so it has become crucial to analyse the phenomenon of vibration and the types of stress it might place on the human body. Mechanical vibrations are produced by the oscillatory movement of a body around a position of equilibrium; they are characterised by frequency $(\mathrm{Hz})$, amplitude $\left(\mathrm{m} / \mathrm{s}^{2}\right)$ and the length of time that the body is exposed to the vibration.

In most cases, vibrations are unwanted effects that can dissipate energy and create noise. The study of the impact of vibrations is very complex [2]-[4]; there are many researchers focused on the effects of vibrations on certain parts of the human body [5], [6]. These studies consist of the analysis and control of all possible ways the vibrations might interfere with the human body to cause discomfort or negatively affect the activities and well-being of a person, including consideration of the effects due to a prolonged exposure over years. There are different effects if the human body is exposed to short-term or long-term vibrations. In the first case, the vibrations cause small physiological effects, such as an increase in heart rate or an increase in muscle tension. In the second case, they produce effects such as alteration of the vertebral column, degenerative processes of the lumbar segments, arthrosis, problems of the digestive system and problems with the genital and urinary system [7], [8].

Some international regulations supervise the exposure of human beings to different sources of vibration. ISO 2631-1 [9] and ISO 5349 [10] are the reference standards for the analysis of 
human exposure to vibrations. The standards define methods and quantify the vibrations transmitted to the body with regard to human health and well-being. The standards do not indicate limits of vibration exposure, but they do describe vibration assessment methods for exposure risk that can be used as a basis for determining these limits. ISO 2631-1 and ISO 5349 each address different types of vibration and different affected body parts:

1) ISO 2631-1 assesses exposure to whole-body vibration (WBV) [11], [12].

2) ISO 5349 evaluates exposure to vibration transmitted to the upper limbs, known as hand-arm vibration or handtransmitted vibration (HTV).

Vibrations transmitted to the whole body can create feelings of discomfort and unease, influencing the standard capacity for human performance or exposing the human body to health risks, such as pathological damage or psychological changes. Stress can occur in different directions, contain many frequencies and vary over time. The standards establish the criteria for measuring the vibrations transmitted to the body, considering the following types: random, periodic and transient vibrations. When the vibrations have frequencies close to the resonance frequencies of the human body, then the harmful effects increase. Consider that the resonance frequency of the spine, which is about $5 \mathrm{~Hz}$, is similar to that produced by many earth-moving machines [13] Within the subset of vehicles, motorcycles represent a vehicle of great interest for the analysis of vibrations due to their increased sensitivity to the roughness of the road when compared to other vehicles [14], [15].

The vibration analysis band for a motorcycle varies from $0.25 \mathrm{~Hz}$ to $20 \mathrm{~Hz}$ [16], [17]. Excitations at very low frequencies (below $0.25 \mathrm{~Hz}$ ) are caused by natural variations in the slope of the road and are not transmitted to the human body. Frequencies above $20 \mathrm{~Hz}$ can be considered noise, which does create different sensations in the body while driving, but these are not caused by the movement of the motorcycle. The remaining frequency range, between $0.25 \mathrm{~Hz}$ and $20 \mathrm{~Hz}$, could also be divided into two other bands: frequencies below $1.5 \mathrm{~Hz}$, which can be set aside due to their low contribution in terms of vibrations, and frequencies from $1.5 \mathrm{~Hz}$ to $20 \mathrm{~Hz}$, which include all the primary vibrations foreseen by the dynamics of a motorcycle [18], [19]. The most significant component affecting the human body's exposure to vibrations during a motorcycle ride is vertical acceleration. Indeed, the inertia forces to which the internal organs of the passenger's body are subjected are proportional to the vertical acceleration, while their relative displacements are influenced by the frequency of excitation [20]. This paper presents an experiment with the use of a wearable device, an object that today is commonly used in everyday life, to evaluate the vibrations transmitted to a human body during a motorcycle ride. Furthermore, the results will be compared those derived from a more typically used fixed accelerometer through the calculation from both of several comfort indexes in the time and frequency domains.

The paper is organised as follows: Section 2 describes the measurement system used for the experiment, Section 3 reports the experimental tests, showing the calculation of several comfort indexes for different types of road, and, finally, sections 4 and 5 present a discussion of the results followed by the conclusion.

\section{THE MEASUREMENT SETUP}

A typical urban motorcycle was used for the evaluation of human body exposure to vibrations during the ride. A suitable data acquisition system was set up, including a wearable device worn by the driver and a data acquisition system able to sample the acceleration data measured on the arm of the driver. A fixed accelerometer mounted across the contact point between the driver's hand and the motorcycle steering was used as a reference for the vibration measurement according to [21]. For more details, see Figure 1.

The measurement system is composed of:

1) Wearable device ST STEVAL-WESU1 (equipped with a 3D accelerometer and a 3D gyroscope LSM6DS3) mounted on the wrist of the driver.

2) STM32F401RE Nucleo board equipped with a Bluetooth module.

3) Fixed accelerometer (LSM6DS3) mounted on the motorcycle's steering.

4) Data logger MDLog (Spring Off).

The wearable device STEVAL-WESU1 [22] includes a MEMS accelerometric sensor for the measurement of accelerations with different ranges: $\pm 2 \mathrm{~g} / \pm 4 \mathrm{~g} / \pm 8 \mathrm{~g} /$ $\pm 16 \mathrm{~g}$. The sensor is characterised by an accuracy equal to $\pm 90 \mathrm{mg}$ at full scale. The acceleration measurements used to evaluate the vibrations transmitted by the motorcycle to the driver would normally be carried out directly on the points of contact between the motorcycle and the driver, but in this experiment, we decided to put the sensible device directly on the driver's arm, as is typical of a wearable device.

The axis reference system of the accelerometer sensor according to the wearable device arrangement (located on the left wrist) is shown in Figure 2. The fixed accelerometer has been mounted at the end of the handlebar.

The STM32F401RE Nucleo board [23] was responsible for the data recording, carried out at the sampling frequency of $400 \mathrm{~Hz}$, which was accomplished through the adoption of several methods of data compression in order to reduce the

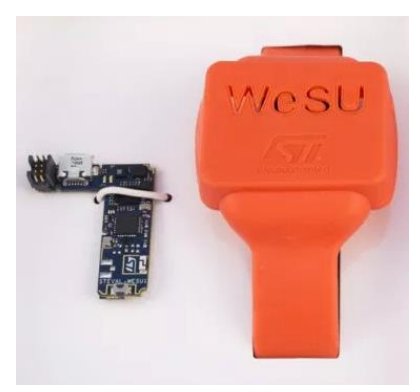

a)

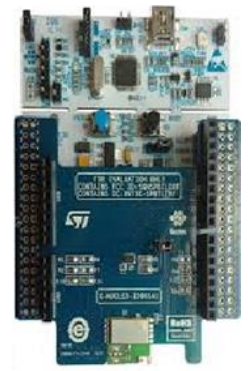

b)

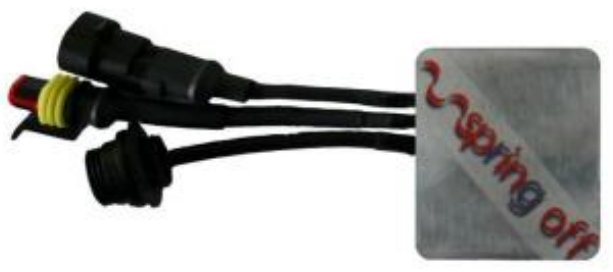

c)

Figure 1. The measurement setup: a) The wearable device, b) The Nucleo board equipped with the Bluetooth module c) The data logger. 


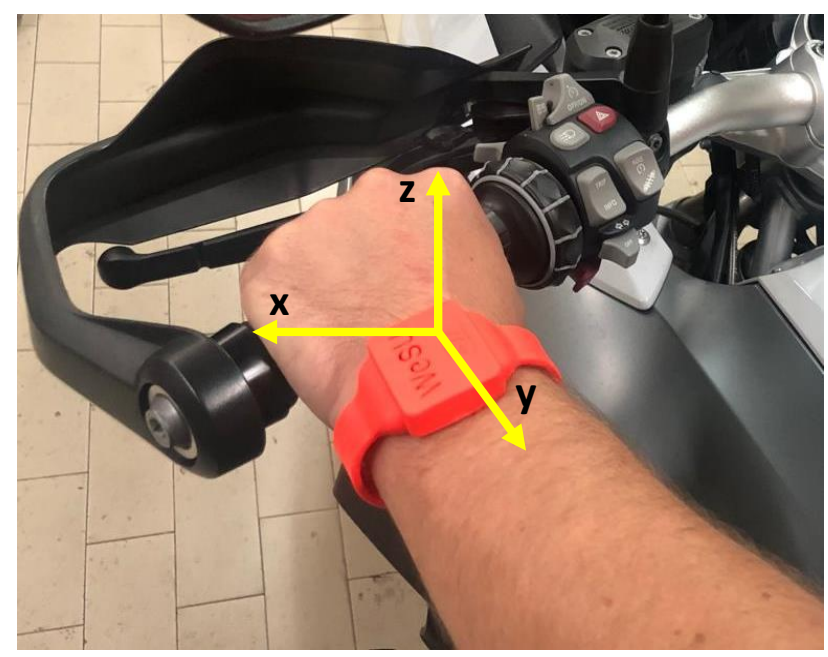

Figure 2 . The reference system for the wearable device.

power consumption and the computational burden [24]-[26]. The communication channels used for data transfer were a Bluetooth bridge with the wearable device and the SPI with the fixed accelerometer. As for data logging, a suitable data acquisition system was designed to store the data collected by the STM32F401RE Nucleo board. The data acquired at a frequency of $400 \mathrm{~Hz}$ are:

1) Acceleration value on the $x$-axis $a_{x}$

2) Acceleration value on the $y$-axis $a_{y}$

3) Acceleration value on the $z$-axis $a_{z}$.

Several tests were carried out on a mixed urban-suburban road, specifically chosen to obtain data on different road surfaces. Data was collected for about $30 \mathrm{~km}$, classifiable by road typology as follows (see Figure 3):

1) $10 \mathrm{~km}$ of urban road with an irregular road surface

2) $10 \mathrm{~km}$ of cobblestone road

3) $10 \mathrm{~km}$ of highway.

\section{EXPERIMENTAL TEST}

As previously explained, considering the massive growth of wearable devices in recent years, the experiment aimed to analyse the use of such a device in the field of human exposure to vibration and compare the results with those obtained from a fixed accelerometer such as would typically be used in the field. Specifically, attention was paid to the vertical accelerations transmitted to the motorcycle driver's body. With this aim, several indexes were evaluated for both accelerometers (i.e. the reference accelerometer and the one included in the wearable device) in order to highlight the annoying frequency components and the daily vibration dose to which the human body is exposed on different road surfaces. In particular, the following indexes were calculated:

- Calculation of HTV in the time domain, which is the RMS acceleration weighted in frequency for the evaluation of comfort concerning an observation window of 8 hours as reported in [10].

- Evaluation of vibration dose value (VDV), useful for the evaluation of vibration transmitted as a result of shock events caused by concentrated obstacles.

- Analysis in the frequency domain of the mean combined auto-spectrum on a range of frequencies of interest.

\subsection{HTV index}

For the measurement of the vibrations generated by the motorcycle and transmitted through the handlebar, we adopted the techniques described in ISO 5349, which estimate the vibrations conducted to the hand-arm system (i.e. the HTV).

The vibration assessment described by the standards is calculated according to the following equation:

$a_{w}=\sqrt{k_{\mathrm{x}}^{2} a_{\mathrm{w}, \mathrm{x}}^{2}+k_{\mathrm{y}}^{2} a_{\mathrm{w}, \mathrm{y}}^{2}+k_{\mathrm{z}}^{2} a_{\mathrm{w}, \mathrm{z}}^{2}}$

where $a_{\mathrm{w}, \mathrm{x}}, a_{\mathrm{w}, \mathrm{y}}, a_{\mathrm{w}, \mathrm{z}}$ are the RMS acceleration components on the three axes weighted in frequency, and $k_{\mathrm{x}}, k_{\mathrm{y}}, k_{\mathrm{z}}$ represent a multiplicative factor defined by ISO 5349 that depends upon the position of the subject and the contact point between the vibrating surface and the body. In our case, those multiplicative factors were considered equal to 1 , as we disregarded the influence of the subject on the contact point [27] and instead considered that all the vibrations generated to the handlebar were transmitted to the driver.

The values of the RMS accelerations $a_{\mathrm{w}, \mathrm{x}}, a_{\mathrm{w}, \mathrm{y}}, a_{\mathrm{w}, \mathrm{z}}$ are calculated for each axis ( $\mathrm{x}, \mathrm{y}$ and $\mathrm{z}$ ) applying a weighting factor according to (2)-(4):

$$
\begin{aligned}
& a_{\mathrm{w}, \mathrm{x}}=\sqrt{\sum_{i}\left(W_{\mathrm{h} i} a_{\mathrm{h} i, \mathrm{x}}\right)^{2}} \\
& a_{\mathrm{w}, \mathrm{z}}=\sqrt{\sum_{i}\left(W_{\mathrm{h} i} a_{\mathrm{h} i, \mathrm{z}}\right)^{2}} \\
& a_{\mathrm{w}, \mathrm{x}}=\sqrt{\sum_{i}\left(W_{\mathrm{h} i} a_{\mathrm{h} i, \mathrm{x}}\right)^{2}}
\end{aligned}
$$

where $a_{\mathrm{h}, \mathrm{x}}, a_{\mathrm{h} i \mathrm{y}}, a_{\mathrm{h} i \mathrm{z}}$ are the accelerations in $\mathrm{m} / \mathrm{s}^{2}$ measured along the $\mathrm{x}, \mathrm{y}$ and $\mathrm{z}$ axes at the $i^{\text {th }}$ frequency; $W_{\mathrm{h} i}$ represents the weighting factors.

Table 1 presents the frequency weighting in terms of the evaluation of HTV laid out in ISO 5349.

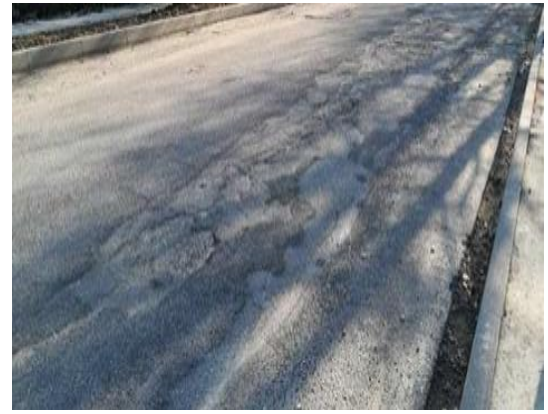

a)

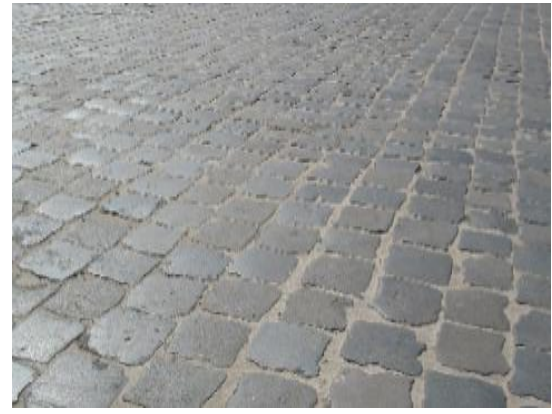

b)

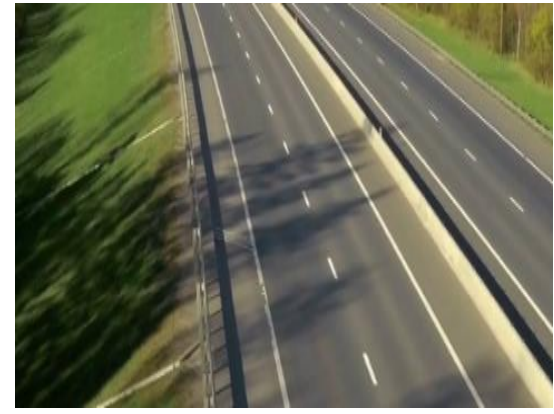

c)

Figure 3. The road experimented: a) Urban road with irregular profile, b) Cobblestones, c) Highway. 
Table 1. Weighting factors for the HTV index.

\begin{tabular}{cc}
\hline Frequencies in $\mathrm{Hz}$ & Weighting factor $\boldsymbol{W}_{\mathrm{hi}}$ \\
\hline 1 & 0.0235 \\
2 & 0.1000 \\
4 & 0.3981 \\
5 & 0.5450 \\
6.3 & 0.7270 \\
8 & 0.8730 \\
10 & 0.9510 \\
12.5 & 0.9580 \\
16 & 0.8760 \\
20 & 0.7820 \\
25 & 0.6470 \\
31.5 & 0.5190 \\
40 & 0.4110 \\
50 & 0.324 \\
\hline
\end{tabular}

The weighting aims to highlight specific, particularly troublesome frequencies for the human body. In the present case, the weighting was carried out as shown in Table 1 , which was extracted from the weighting curve reported in ISO 5349. The application of the table consisted of filtering the acceleration signal with an appropriate set of filters centred in the next $i$ th frequency defined in Table 1.

The acceleration signal was filtered for each $i$ th band to calculate the value $a_{\text {hix,hiy,hiz. Finally, the acceleration was }}$ multiplied for the $i$ th frequency with the appropriate weighting value $W_{\text {hi }}$ according to Table 1 .

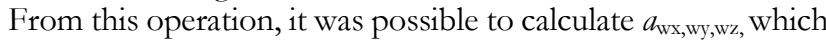
represents the frequency-weighted RMS acceleration along the three $\mathrm{x}, \mathrm{y}, \mathrm{z}$ axes.

The index, calculated for the three orthogonal directions $\mathrm{x}, \mathrm{y}$, $z$, was combined into a single index that defined the effective value of the frequency-weighted acceleration expressed as a combination of the accelerations measured in each direction using (1).

The HTV index was calculated for each road profile by considering consecutive time windows of $30 \mathrm{~s}$ in order to achieve a set of 30 values, the mean value and corresponding standard deviation of which are summarised in Table 2. Moreover, the percentage coefficient of variation (CoV, i.e. the standard deviation normalised to the mean value) for each result is reported.

\subsection{VDV index}

The VDV index was evaluated when the motorcycle crossed a concentrated obstacle, which was a generic bump such as is often encountered in an urban scenario (see Figure 4).

To analyse the data of interest, a 3-second time window centred from the peak of the oscillation was taken, and 20 tests were considered. The VDV is a parameter used for the

Table 2. HTV indexes calculated on different types of roads with the proposed measurement setup.

\begin{tabular}{ccccccc}
\hline Typology & \multicolumn{3}{c}{ Fixed accelerometer } & \multicolumn{3}{c}{ Wearable device } \\
\hline & Mean & Std & CoV & Mean & Std & CoV \\
& in $\mathrm{m} / \mathrm{s}^{2}$ & in $\mathrm{m} / \mathrm{s}^{2}$ & in $\%$ & in $\mathrm{m} / \mathrm{s}^{2}$ & in $\mathrm{m} / \mathrm{s}^{2}$ & in \% \\
Cobblestone & 2.58 & 0.15 & 6 & 3.07 & 0.11 & 4 \\
Highway & 2.64 & 0.10 & 4 & 1.69 & 0.05 & 3 \\
Urban & 4.48 & 0.18 & 4 & 1.55 & 0.07 & 4 \\
\hline
\end{tabular}

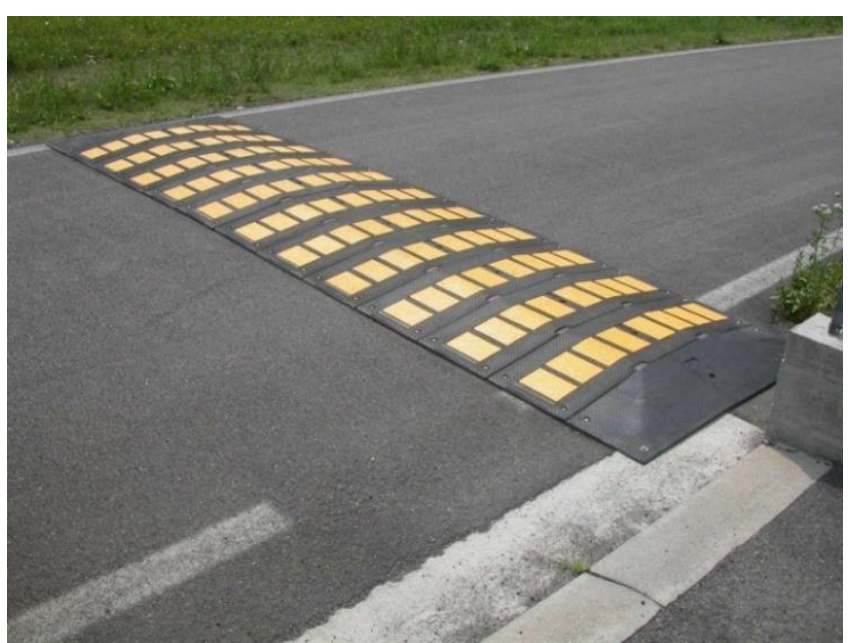

Figure 4. The bump used for the calculation of the VDV index.

assessment of comfort in case of vibrations due to shock events caused by a concentrated obstacle such as a bump. The mathematical equation used to calculate the VDV index is the following:

$V D V=\sqrt[4]{\frac{1}{T} \int_{0}^{T_{S}} a_{\mathrm{w}}^{4}(t) d t}$

where $T_{\mathrm{s}}$ is the duration of the observation window expressed in seconds and $a_{\mathrm{w}}(t)$ is the measured acceleration. Specifically, the calculation uses the fourth power of acceleration, which, compared to the RMS value, is more sensitive to the peaks generated by these shock events. Passing over the concentrated obstacle will generate a spike on the acquired dataset of accelerations, which can be seen from the graph reported in Figure 5. For example, it is possible to recognise the peak of accelerations at around $35.3 \mathrm{~s}$ on the acquisition record. The mean VDV index calculated with both of the accelerometers is reported in Table 3 along with the corresponding standard deviation and percentage $\mathrm{CoV}$.

\subsection{Frequency Domain Analysis}

The index analysed is the combined medium spectrum, calculated from the signals measured by the accelerometers during 15 minutes of data acquisition. In detail, the autospectrum was calculated by applying the discrete Fourier transform (DFT) to the signal samples and multiplying the value obtained by its conjugated complex, as reported in (6):

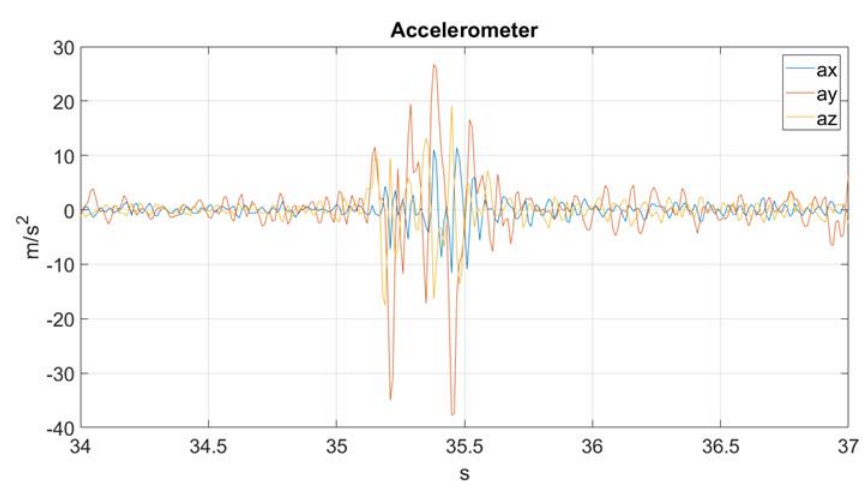

Figure 5. Spike in the acceleration signal due to a bump. 
Table 3. VDV indexes calculated by the devices under test.

\begin{tabular}{ccc|ccc}
\hline \multicolumn{3}{c|}{ Fixed accelerometer } & \multicolumn{3}{c}{ Wearable device } \\
\hline Mean & Std & CoV & Mean & Std & CoV \\
in $\mathrm{m} / \mathrm{s}^{1.75}$ & in $\mathrm{m} / \mathrm{s}^{1.75}$ & in $\%$ & in $\mathrm{m} / \mathrm{s}^{1.75}$ & in $\mathrm{m} / \mathrm{s}^{1.75}$ & in $\%$ \\
2.25 & 0.08 & 4 & 4.39 & 0.64 & 14 \\
\hline
\end{tabular}

$S_{x x}=A(f) \cdot A^{*}(f)$

where $A(f)$ is the Fourier transform of the signal, and $A^{*}(f)$ is the complex conjugate of $A(f)$.

The auto-spectrums were calculated for each axis of the accelerometers $\mathrm{x}, \mathrm{y}, \mathrm{z}$ (the data pre-processing was performed through the application of a suitable high pass filter aiming to suppress the continuous component). Subsequently, the individual auto-spectrums were combined using the following formula:

$S_{\mathrm{comb}}=\sqrt{S_{\mathrm{xx}}^{2}+S_{\mathrm{yy}}^{2}+S_{z z}^{2}}$

where $S_{\mathrm{xx}}$ is the auto-spectrum in the direction $\mathrm{x}, S_{\mathrm{yy}}$ is the autospectrum in the direction $y$ and, finally, $S_{z z}$ is the auto-spectrum in the direction $z$.

Finally, the quantitative evaluation was performed, considering as an objective index the integral of the autospectrum calculated in the frequency range $0 \mathrm{~Hz}$ to $50 \mathrm{~Hz}$ :

$I=\int_{0}^{50} S_{\text {comb }} \mathrm{d} f$

The frequency range was selected to highlight through the combined spectrum the expected vibration peaks associated with:

- Frequency of suspended masses

- Frequency of unsuspended masses

- Frame frequencies

As an example, the combined spectrum of the signals measured by the fixed accelerometer is reported in Figure 6.

The frequency analysis was performed in such a way as to calculate the integral $I(8)$ of the combined average spectra for each type of road. The results are reported in Table 4 in terms of the mean value, standard deviation and percentage $\mathrm{CoV}$ derived from 30 samples of the integral $I(8)$.

\section{DISCUSSION OF RESULTS}

The experimental results summarised in Table 2-Table 4 show the satisfying data quality of the measurement campaign, as highlighted by the limited coefficient of variation exhibited by the proposed indexes, particularly when computed on the signal outputs from the wearable device $(\mathrm{CoV}<15 \%)$. Moreover, as determined by a mean test with a confidence level not lower than

Table 4. Auto-spectrum indexes calculated on different types of roads with the proposed measurement setup.

\begin{tabular}{lcccccc}
\hline Typology & \multicolumn{3}{c}{ Fixed accelerometer } & \multicolumn{3}{c}{ Wearable device } \\
\hline & Mean & Std & CoV & Mean & Std & CoV \% \\
in $\mathrm{m}^{2} / \mathrm{s}^{5}$ & in $\mathrm{m}^{2} / \mathrm{s}^{5}$ & in $\%$ & in $\mathrm{m}^{2} / \mathrm{s}^{5}$ & in $\mathrm{m}^{2} / \mathrm{s}^{5}$ & in \% \\
Cobblestone & 0.97 & 0.18 & 19 & 1.09 & 0.04 & 4 \\
Highway & 1.03 & 0.33 & 32 & 0.36 & 0.05 & 14 \\
Urban & 1.55 & 0.54 & 35 & 0.38 & 0.03 & 9 \\
\hline
\end{tabular}

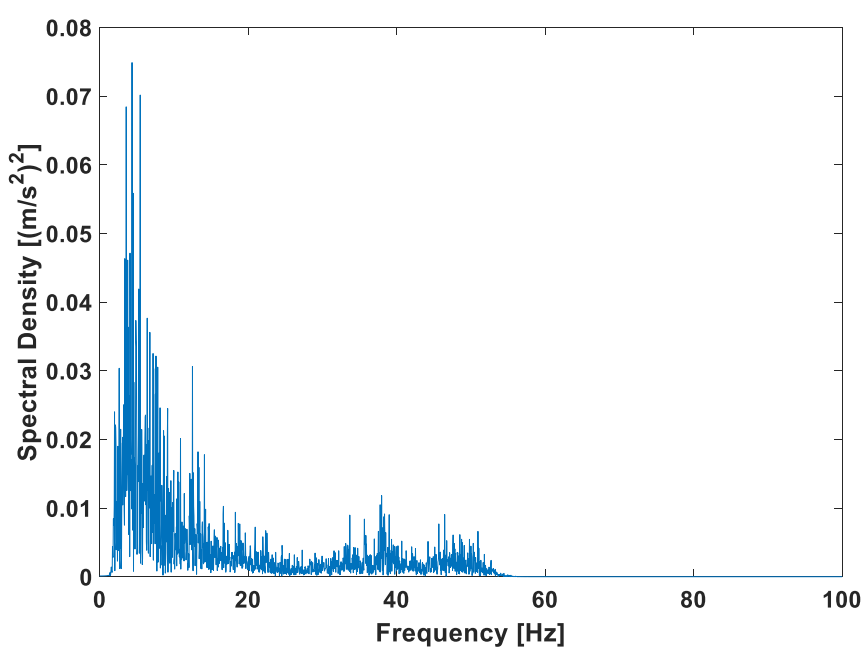

Figure 6 . The spectrum of the acceleration signal.

$95 \%$ for the varying road typology, the corresponding values for each index type are statistically significant since they result from different distribution (i.e. the null hypothesis $\mathrm{H}_{0}$, according to which two indexes may result from the same population, is refused regardless of which combination of device and/or road typology is considered).

As already highlighted in [21], the HTV index was shown to be the most reliable and significant, since:

- similar results in terms of small $\mathrm{CoV}(<10 \%)$ are exhibited with both the devices under test;

- the greatest span is exhibited for each device when different road typologies are considered, making it easier to identify the corresponding discomfort levels.

Moreover, all three indexes confirm that the comfort level as interpreted by the device on the driver's wrist is strongly influenced by the roughness of the road, which may be assumed to be the primary source of vibration at the lowest frequencies and motorcycle speeds. Indeed, with regard to the wearable device, all three indexes assume the most significant value in evaluation of the ride on cobblestone (here we assume as similar the behaviour exhibited in correspondence with the bump). Furthermore, for the first road type, both the HTV and the (combined spectrum integral) $I$ index are characterised by greater value when both devices under test are compared, whereas the opposite behaviour is exhibited when riding on urban and highway roads is considered. In other words, both the time domain and frequency domain analysis highlight that the vibrations transmitted to the hand (as measured by the fixed accelerometer) while riding a motorcycle at high speed increase with the influence of the aerodynamics and the contribution of the frame vibration; these components are more significant than the vertical dynamics introduced by the road roughness. At the same time, the former vibration contribution is muffled by the driver mass, which reduces the corresponding index values computed on the signals outputted from the wearable device.

\section{CONCLUSIONS}

The evaluation of the vibration transfer to the human body during a motorcycle ride is of considerable interest in order to give relevant information to the rider about the stress accumulated during a ride. Considering the technological progress regarding the development of new tiny and wearable technologies, the paper focuses on the feasibility of the use of a 
typical wearable device (smartwatch) for the calculation of HTV indexes for different road profiles. From the time and frequency domain analysis represented by the most commonly adopted indexes, it is clear that the highest value of vibration is relative to the cobblestone; thus, a long ride on a road surface of this type will create more significant discomfort. Conversely, driving the motorcycle on a suburban road will involve less discomfort. Considering all the results described, the method is also useful for the evaluation of the quality of the road surface that a driver is obliged to use for daily commuting in order to give feedback and choose the best road for reduced exposure to vibrations (for example a suburban road instead of a highway). The measurement system described could also be used for the evaluation of the vertical vibration reduction introduced by a semi-active suspension system [28] instead of the classical suspension system in a motorcycle or for the detection of faults in a suspension system [29]-[32]. Indeed, the use of wearable devices (as opposed to the installation of expensive fixed sensors) offers the possibility of calculating the HTV index in real time (the most reliable method) for different kinds of vehicles, just by wearing a smartwatch. On the other hand, the main hypothesis of the proposal is the fixed position of the wearable device on the left wrist. Different installation positions should be investigated in order to give the end-user a multiplicative coefficient for the correction of the index.

Future research will also concern the analysis WBV according to ISO 2631-1: it will be investigated by introducing other wearable devices (i.e. foot pods) as well as an accelerometric sensor between the driver's body and the motor vehicle seat and combining the results with the analysis proposed in this work.

\section{REFERENCES}

[1] B. O. Wikström, A. Kjellberg, U. Landström, Health effects of long-term occupational exposure to whole-body vibration: A review, International Journal of Industrial Ergonomics 14(4) (1994) pp. 273-292.

DOI: https://doi.org/10.1016/0169-8141(94)90017-5

[2] K. Krajnak, Health effects associated with occupational exposure to hand-arm or whole-body vibration, Journal of Toxicology and Environmental Health, Part B. 21 (2018) pp. 1-15. DOI: https://doi.org/10.1080/10937404.2018.1557576

[3] I. Bodini, M. Lancini, S. Pasinetti, D. Vetturi, Techniques for onboard vibrational passenger comfort monitoring in public transport, Acta IMEKO 3(4) (2014) pp. 32-37.

DOI: https://doi.org/10.21014/acta imeko.v3i4.152

[4] F. Crenna, G. B. Rossi, Measurements for the evaluation of vibration exposure of operators in a ship container terminal, 19th IMEKO World Congress, Lisbon, Portugal, 6 - 11 September 2009, vol. 4, pp. 2336-2341. Online [Accessed 3 November 2020] https://www.imeko.org/publications/wc-2009/IMEKO-WC2009-TC22-431.pdf

[5] X. Linan, E. Zhang, L. Mingli, S. Xiaochun, Z. Fan, Human vibration characteristic and experiment research on man-machine system in dynamic environment, $9^{\text {th }}$ International Conference on Computer-Aided Industrial Design and Conceptual Design, Kunming, China, 2008, pp. 169-174.

DOI: https://doi.org/10.1109/CAIDCD.2008.4730545

[6] R. Yanxi, L. Qingxia, Implementation of human vibration test and evaluation system based on virtual instrument, International Conference on Mechanic Automation and Control Engineering, Wuhan, China, 2010, pp. 2430-2435.

DOI: https://doi.org/10.1109/MACE.2010.5535864

[7] G. S. Paddan, M. J. Griffin, Evaluation of whole-body vibration in vehicles, Journal of Sound and Vibration 253(1) (2002) pp. 195213.

DOI: https://doi.org/10.1006/isvi.2001.4256
[8] M. Griffin, Handbook of human vibration, Academic Press, 1990, ISBN 978-0-12-303040-5 DOI: https://doi.org/10.1016/C2009-0-02730-5

[9] ISO, International Standard ISO 2631-1, 1997.

[10] ISO, International Standard ISO 5349, 2001.

[11] R. Rosenkranz, S. Gruschwitz, M. Wilberg, M. E. Altinsoy, S. Merchel, Identification and evaluation of perceptual attributes for periodic whole-body and hand-arm vibration, Lecture Notes in Computer Science (including subseries Lecture Notes in Artificial Intelligence and Lecture Notes in Bioinformatics) 10893 (2018) pp 113-124.

[12] Z. Jelačić, B. Pikula, Vibration analysis of motorcycle handles, Lecture Notes in Networks and Systems 42 (2019) pp. 196-201.

[13] A. Kumar, M. Varghese, D. Mohan, P. Mahajan, P. Gulati, S. Kale, Effect of whole-body vibration on the low back: A study of tractor-driving farmers in North India, Spine 24(23) (1999) pp. 2506.

[14] D. Yuan, X. Zheng, Y. F. B. Yang, Modeling and simulation of motorcycle ride comfort based on bump road, Advanced Materials Research 139-141 (2010) pp. 2643-2647.

[15] C. Poussot-Vassal, C. Spelta, O. Sename, S. M. Savaresi, L. Dugard, Survey and performance evaluation on some automotive semi-active suspension control methods: A comparative study on a single-corner model, Annual Reviews in Control 36(1) (2012) pp. 148-160.

[16] C. Liguori, V. Paciello, A. Paolillo, A. Pietrosanto, P. Sommella, Characterization of motorcycle suspension systems: Comfort and handling performance evaluation, IEEE Instrumentation and Measurement Technology Conference, Minneapolis, USA, 6 - 9 May 2013, pp. 444-449.

DOI: https://doi.org/10.1109/I2MTC.2013.6555457

[17] M. Carratù, A. Pietrosanto, P. Sommella, V. Paciello, Velocity prediction from acceleration measurements in motorcycle suspensions, IEEE International Instrumentation and Measurement Technology Conference (I2MTC), Turin, Italy, 2017, pp. 1-6.

DOI: https://doi.org/10.1109/I2MTC.2017.7969943

[18] M. Carratù, A. Pietrosanto, P. Sommella, V. Paciello, Measuring suspension velocity from acceleration integration, IEEE $16^{\text {th }}$ International Conference on Industrial Informatics (INDIN), Porto, Portugal, 2018, pp. 933-938.

DOI: https://doi.org/10.1109/INDIN.2018.8472039

[19] C. Liguori, V. Paciello, A. Paolillo, A. Pietrosanto, Real-time detection of low frequency components, IEEE Trans. Instrum. Meas., 62(5) (2013) pp. 1118-1129.

[20] J. Pellettiere, J. Crocco, K. Jackson, Rotorcraft full spectrum crashworthiness and occupant injury requirements, Annual Forum Proceedings - AHS International 2 (2011) pp. 919-930.

[21] M. Carratu, A. Pietrosanto, P. Sommella, V. Paciello, A wearable low-cost device for measurement of human exposure to transmitted vibration on motorcycle, Proceedings of the IEEE International Workshop on Metrology for Industry 4.0 and IoT, MetroInd 4.0 and IoT, Naples, Italy, 4 - 6 June 2019, pp. 329-333. DOI: https://doi.org/10.1109/METROI4.2019.8792855

[22] STMicroelectronics, Wearable sensor unit reference design for fast time to market, Online [Accessed 29 October 2020] https://www.st.com/en/evaluation-tools/steval-wesu1.html

[23] STMicroelectronics, STM32 Dynamic Efficiency MCU, Online [Accessed 29 October 2020] https://www.st.com/en/microcontrollersmicroprocessors/stm32f401 re.html

[24] L. Angrisani, F. Bonavolonta, M. D'Apuzzo, R. Schiano Lo Moriello, M. Vadursi, A compressive sampling based method for power measurement of band-pass signals, IEEE International Instrumentation and Measurement Technology Conference (I2MTC), Minneapolis, USA, 6 - 9 May 2013, pp. 102-107. DOI: https://doi.org/10.1109/I2MTC.2013.6555390

[25] L. Angrisani, F. Bonavolonta, R. Schiano Lo Moriello, A. Andreone, R. Casini, G. Papari, D. Accardo, First steps towards an innovative compressive sampling based-THz imaging 
system for early crack detection on aereospace plates, 2014 IEEE Metrology for Aerospace (MetroAeroSpace), Benevento, Italy, 2014, pp. 488-493.

DOI: https://doi.org/10.1109/MetroAeroSpace.2014.6865974

[26] S. Krug, M. O'Nils, Modeling and Comparison of Delay and Energy Cost of IoT Data Transfers, in IEEE Access 7 (2019) pp. 58654-58675.

DOI: https://doi.org/10.1109/ACCESS.2019.2913703

[27] R. Taiar, C. B. Machado, X. Chiementin, M. Bernardo-Filho, Whole Body Vibrations: Physical and Biological Effects on the Human Body, CRC Press, Boca Raton, 2018, ISBN 9781138500013.

[28] M. Carratù, A. Pietrosanto, P. Sommella, V. Paciello, Semi-active suspension system for motorcycles: From the idea to the industrial product, IEEE International Instrumentation and Measurement Technology Conference (I2MTC), Houston, USA, 14 - 17 May 2018, pp. 1-6.

DOI: https://doi.org/10.1109/I2MTC.2018.8409829
[29] D. Capriglione, M. Carratù, P. Sommella, A. Pietrosanto, ANNbased IFD in motorcycle rear suspension, Proc. $15^{\text {th }}$ IMEKO, Budapest, Hungary, June 2017, pp. 1-5.

[30] D. Capriglione, M. Carratù, A. Pietrosanto, P. Sommella, Realtime implementation of an IFD scheme for motorcycle sensors, IEEE International Instrumentation and Measurement Technology Conference (I2MTC), Houston, USA, 14 - 17 May 2018, pp. 1-6.

DOI: https://doi.org/10.1109/I2MTC.2018.8409833

[31] M. Catelani, L. Ciani, V. Luongo, R. Singuaroli, Evaluation of the Safe Failure Fraction for an electromechanical complex system: remarks about the standard IEC61508, IEEE Instrumentation \& Measurement Technology Conference Proceedings, Austin, USA, 3- 6 May 2010, pp. 949-953.

DOI: https://doi.org/10.1109/IMTC.2010.5488034

[32] D. Capriglione, M. Carratù, A. Pietrosanto, P. Sommella, Online fault detection of rear stroke suspension sensor in motorcycle, IEEE Transactions on Instrumentation and Measurement 68 no. 5 (2019) pp. 1362-1372.

DOI: https://doi.org/10.1109/TIM.2019.2905945 